\title{
Editorial
}

\section{Special Issue on Indoor Air Quality}

\author{
Dikaia E. Saraga \\ National Center for Scientific Research “Demokritos", Aghia Paraskevi, 15310 Athens, Greece; \\ dsaraga@ipta.demokritos.gr
}

Received: 8 February 2020; Accepted: 11 February 2020; Published: 22 February 2020

\section{Introduction}

It is a fact that people in developed countries spend almost $90 \%$ of their time indoors, where they experience their greatest exposures. However, regulation of air pollution focuses on outdoor air, as indoor environment is less well-characterized and recognized as a potential location for exposure to air pollution.

What makes indoor air intrinsically more interesting than outdoor air from a scientific point of view? Some sources are undoubtedly uniquely building-related (e.g., cleaning agents, emissions from building materials and personal care products), while some contaminant dynamics operate only in buildings (e.g., the distribution of particles and gases by mechanical ventilation systems and photochemical reactions, and the infiltration of soil gases). Besides this, air pollutant concentrations are often higher indoors than outdoors, particularly following activities such as cleaning and cooking (with a greater source strength indoors than outdoor on a per area basis), while it has already been proven that many indoor air pollutants are harmful to human health.

Another issue is ventilation. While indoor microenvironments are a microcosm of most urban settings, the effective air exchange and renewal in buildings is much lower than outdoors, even in urban areas. This concern is amplified by the fact that energy efficiency measures, driven by climate change awareness, have made modern buildings more airtight, further degrading the quality of indoor air. Therefore, a person is significantly more likely to inhale a harmful chemical molecule if it is emitted indoors rather than outdoors.

Monitoring of indoor air pollutants in a spatio-temporal basis is challenging. A key element is the access to local (i.e., indoor residential, workplace, or public building) exposure measurements. Unfortunately, the high cost and complexity of most current air pollutant monitors results in a lack of detailed spatial and temporal resolution. Therefore, individuals of vulnerable groups (children, pregnant, elderly, and sick people) have little insight into their personal exposure levels. This becomes significant in cases of hyper-local variations and short-term pollution events such as instant indoor activity (e.g., cooking, smoking, and dust resuspension). Advances in sensor miniaturization have encouraged the development of small, inexpensive devices capable of estimating pollutant concentrations. This new class of sensors presents new possibilities for indoor exposure monitoring.

Furthermore, indoor air chemistry models typically account for air exchange with outdoors through ventilation, deposition on indoor surfaces, and photochemical reactions. Surface chemistry on furnishings, building materials, and human bodies is becoming increasingly recognized as being of crucial importance.

In light of the above, this Special issue on 'Indoor Air Quality' was introduced to collect latest research and address challenging issues in the areas of the triptych: Indoor environment quality monitoring, indoor air modeling, and exposure to indoor air pollution. 


\section{From Indoor Environment Quality Perception to Indoor Air Quality Monitoring and Control}

In this Special Issue, 24 papers were submitted, and 16 were accepted for publication $(67 \%$ acceptance rate). $63 \%$ of the published studies originate from Europe, while $37 \%$ of them were conducted in Asiatic countries. Various topics have been addressed in the contributed articles: Indoor air quality (IAQ) monitoring and modelling, occupants' comfort related to indoor environment parameters as well as innovative techniques for IAQ monitoring and improvement. When looking back, it can be concluded that the majority of the studies can be distinguished into two main groups. The first one refers to occupants' perception for the quality of the indoor environment as well as their comfort inside a building. The second group focuses on new techniques of monitoring and controlling the parameters determining the quality of indoor air. Finally, a quite smaller group includes studies performed in indoor environments of special characteristics.

To be more specific, nine papers discuss the issues of IAQ perception and control as well as thermal comfort. The study of M. Cho and M. Kim, [1] titled 'Residents' Perceptions of and Response Behaviors to Particulate Matter-A Case Study in Seoul, Korea' aimed at understanding the perception of 171 people in Seoul for indoor air quality based on domestic particulate matter levels. In a European-scale study titled 'Personal Control of the Indoor Environment in Offices: Relations with Building Characteristics, Influence on Occupant Perception and Reported Symptoms Related to the Building-The Officair Project', Sakellaris I. et al. [2] focused on revealing the complex relationship between office employees' control over various indoor environment parameters and their comfort, health and productivity. 7441 occupants of 167 recently built or retrofitted office buildings in eight European countries participated in an online survey about personal/health/work data as well as physical/psycho-social information. In another study titled 'An Investigation of the Effects of Changes in the Indoor Ambient Temperature on Arousal Level, Thermal Comfort, and Physiological Indices', Gwak J. et al. [3] aimed to design a thermal environment that improves both the arousal level and thermal comfort of the occupants. To this end, they investigated the relationships between the physiological indices, subjective evaluation values, and task performance under several conditions of changes in the indoor ambient temperature. The study 'Probability of Abnormal Indoor Air Exposure Categories Compared with Occupants' Symptoms, Health Information, and Psychosocial Work Environment' authored by Tähtinen K. et al. [4] aimed at (i) evaluating the relation between the four-level categorized probability of abnormal indoor air exposure and employees' work environment-related symptoms, group-level health information, and psychosocial work environment, (ii) assessing the relation between ventilation system deficiencies and employees' work environment-related symptoms and evaluating the impact of prolonged IAQ problem solution processes on perceived IAQ. The study 'Combined Model for IAQ Assessment: Part 1-Morphology of the Model and Selection of Substantial Air Quality Impact Sub-Models' of Piasecki M. and Kostyrko K.B. [5] provided an overview of models defining occupants' comfort and satisfaction with IAQ. Specifically, subcomponents of three potential IAQ models were classified according to their application potential: IAQ quality index, IAQ comfort index, and an overall health and comfort index. The authors provide a method for using the combined IAQ index to determine the indoor environmental quality index, IEQ and a practical case study which provides IAQ and IEQ model implementation for a large office building assessment. The study titled 'An Accident Model with Considering Physical Processes for Indoor Environment Safety' authored by Yang Z. et al. [6] also deals with thermal comfort in an indoor environment. In particular, authors presented an extension of Systems-Theoretic Accident Model and Process (STAMP) while considering physical processes in an indoor environment as temperature changes. Thermal comfort was also the subject of the study of Cheng X. et al. [7] titled 'A Contactless Measuring Method of Skin Temperature based on the Skin Sensitivity Index and Deep Learning'. In this study, a skin sensitivity index was proposed to describe individual sensitivity of thermal comfort, and the index was combined with skin images for deep learning network training. Also, a novel contactless measuring algorithm (NISDL) based on SSI was proposed, with two different frameworks of NISDL having been designed for real-time thermal comfort measurements. Finally, a deep learning algorithm without SSI was also generated and trained. Two more studies have worked on the evaluation of the 
indoor environment quality while focusing on a specific population group: Children and teenagers. The study of Mainka A. and Zajusz-Zubek E., [8] named 'Keeping Doors Closed as One Reason for Fatigue in Teenagers-A Case Study' investigated the variability of $\mathrm{CO}_{2}$ concentration in naturally ventilated bedrooms of teenagers in Polland, by correlating bedroom door opening during the night with $\mathrm{CO}_{2}$ concentration and thermal comfort. In the study 'Cooking/Window Opening and Associated Increases of Indoor PM2.5 and $\mathrm{NO}_{2}$ Concentrations of Children's Houses in Kaohsiung, Taiwan', Yen Y. et al. [9] attempted to assess the influence of window opening and cooking activity to measured air pollutants levels in 60 children homes in an industrial city in Taiwan.

The second sub-group of papers published in this Special Issue, includes five studies which feature the introduction of new developments in technology and computational science to the field of indoor environment monitoring and control. The study of Kim S. et al. [10] titled 'Evaluation of Performance of Inexpensive Laser Based PM2.5 Sensor Monitors for Typical Indoor and Outdoor Hotspots of South Korea' presents the results of the evaluation of a low-cost real-time PM monitor under indoor testing with common $\mathrm{PM}_{2.5}$ sources of Korea (frying pork in a pan or smoking). In another study, 'Real-Time Monitoring of Indoor Air Quality with Internet of Things-Based E-Nose', authored by Tastan M. [11] and Gokozan $\mathrm{H}$., an 'e-nose', a real-time mobile air quality monitoring system with various air parameters such as $\mathrm{CO}_{2}, \mathrm{CO}, \mathrm{PM} 10, \mathrm{NO}_{2}$ temperature and humidity was presented and evaluated. The proposed e-nose is produced with an open source, low cost, easy installation and do-it-yourself approach. An environmental quality solution based on IoT to supervise Laboratory Environmental Conditions (LEC) named $i A Q+$ was introduced in the paper titled 'An Internet of Things-Based Environmental Quality Management System to Supervise the Indoor Laboratory Conditions' authored be Marques C. and Pitarma $R$ [12]. This low-cost wireless solution for indoor environment quality supervision incorporates mobile computing technologies for data consulting, easy installation, significant notifications for enhanced living conditions, and laboratory activities. Further, Cheng X. et al. [7] study (presented in the previous paragraph) belongs to this sub-group as it included training of deep learning network. Finally, the study 'A Promising Technological Approach to Improve Indoor Air Quality' authored by Maggos T. et al. [13] presents an innovative paint material which exhibits intense photocatalytic activity under direct and diffused visible light for the degradation of air pollutants, suitable for indoor use. This innovative photo-paint was tested under laboratory and real scale conditions.

Last but not least, three papers published in this Special Issue include studies of air quality in indoor environments of special characteristics. The first one, 'Study of Passive Adjustment Performance of Tubular Space in Subway Station Building Complexes' by Li J. et al. [14] focused on the various tubular space forms in subway station building complexes with the scope of proposing an improvement of the indoor environment in terms of comfort and energy consumption. The second one, 'Application of Airborne Microorganism Indexes in Offices, Gyms, and Libraries' authored by Grisoli P. et al. [15] quantified the levels of microorganisms present in the air in different places such as offices, gyms, and libraries. The third one, 'How Working Tasks Influence Biocontamination in an Animal Facility' authored by Marcelloni M. et al. [16] aimed to determine what factors could be associated with a high level of exposure to biological agents in an animal facility, through the measuring and characterization of airborne fungi, bacteria, endotoxin, (1,3)- $\beta$-D-glucan and animal allergens.

\section{Conclusions}

As a final point, the papers in this Special Issue have pinpointed two thematic areas of IAQ that researchers currently focus on, and basically, answer two questions: (i) How do people perceive the quality of air inside their home, office, school etc.? and (ii) what are the state of the art tools (both instrumentational and computational) to monitor, control and improve indoor air quality? While this Special Issue has been closed, further research towards these directions is expected in the very near future. There are still several challenging research questions to be answered. Manuscripts addressing challenging future research for Indoor Air Quality are invited in the second volume, named 'New Challenges for Indoor Air Quality' launched by Applied Sciences, MDPI. 
Author Contributions: D.E.S. performed the papers' review and wrote the editorial. The author has read and agreed to the published version of the manuscript.

Acknowledgments: This issue would not be possible without the contributions of various talented authors, hardworking and professional reviewers, and dedicated editorial team of Applied Sciences. Congratulations to all authors-no matter what the final decisions of the submitted manuscripts were, the feedback, comments, and suggestions from the reviewers and editors which substantially helped the authors to improve their papers. Finally, I place on record my gratitude to the editorial team of Applied Sciences, and special thanks to Daria Shi, Assistant Editor from MDPI Branch Office, Beijing.

Conflicts of Interest: The authors declare no conflict of interest.

\section{References}

1. Cho, M.; Kim, M. Residents' perceptions of and response behaviors to particulate matter-A case study in Seoul, Korea. Appl. Sci. 2019, 9, 3660. [CrossRef]

2. Sakellaris, I.; Saraga, D.; Mandin, C.; de Kluizenaar, Y.; Fossati, S.; Spinazzè, A.; Cattaneo, A.; Szigeti, T.; Mihucz, V.; de Oliveira Fernandes, E.; et al. Personal control of the indoor environment in offices: Relations with building characteristics, influence on occupant perception and reported symptoms related to the building-The officair project. Appl. Sci. 2019, 9, 3227. [CrossRef]

3. Gwak, J.; Shino, M.; Ueda, K.; Kamata, M. An investigation of the effects of changes in the indoor ambient temperature on arousal level, thermal comfort, and physiological indices. Appl. Sci. 2019, 9, 899. [CrossRef]

4. Tähtinen, K.; Lappalainen, S.; Karvala, K.; Lahtinen, M.; Salonen, H. Probability of abnormal indoor air exposure categories compared with occupants' symptoms, health information, and psychosocial work environment. Appl. Sci. 2019, 9, 99. [CrossRef]

5. Piasecki, M.; Kostyrko, K. Combined model for IAQ assessment: Part 1-Morphology of the model and selection of substantial air quality impact sub-models. Appl. Sci. 2019, 9, 3918. [CrossRef]

6. Yang, Z.; Lim, Y.; Tan, Y. An accident model with considering physical processes for indoor environment safety. Appl. Sci. 2019, 9, 4732. [CrossRef]

7. Cheng, X.; Yang, B.; Tan, K.; Isaksson, E.; Li, L.; Hedman, A.; Olofsson, T.; Li, H. A Contactless measuring method of skin temperature based on the skin sensitivity index and deep learning. Appl. Sci. 2019, 9, 1375. [CrossRef]

8. Mainka, A.; Zajusz-Zubek, E. Keeping doors closed as one reason for fatigue in teenagers-A case study. Appl. Sci. 2019, 9, 3533. [CrossRef]

9. Yen, Y.; Yang, C.; Mena, K.; Cheng, Y.; Chen, P. Cooking/window opening and associated increases of indoor PM2.5 and $\mathrm{NO}_{2}$ concentrations of children's houses in kaohsiung, Taiwan. Appl. Sci. 2019, 9, 4306. [CrossRef]

10. Kim, S.; Park, S.; Lee, J. Evaluation of performance of inexpensive laser based PM2.5 sensor monitors for typical indoor and outdoor hotspots of south Korea. Appl. Sci. 2019, 9, 1947. [CrossRef]

11. Taştan, M.; Gökozan, H. Real-time monitoring of indoor air quality with internet of things-based E-nose. Appl. Sci. 2019, 9, 3435. [CrossRef]

12. Marques, G.; Pitarma, R. An internet of things-based environmental quality management system to supervise the indoor laboratory conditions. Appl. Sci. 2019, 9, 438. [CrossRef]

13. Maggos, T.; Binas, V.; Siaperas, V.; Terzopoulos, A.; Panagopoulos, P.; Kiriakidis, G. A promising technological approach to improve indoor air quality. Appl. Sci. 2019, 9, 4837. [CrossRef]

14. Li, J.; Lu, S.; Wang, Q.; Tian, S.; Jin, Y. Study of passive adjustment performance of tubular space in subway station building complexes. Appl. Sci. 2019, 9, 834. [CrossRef]

15. Grisoli, P.; Albertoni, M.; Rodolfi, M. Application of airborne microorganism indexes in offices, gyms, and libraries. Appl. Sci. 2019, 9, 1101. [CrossRef]

16. Marcelloni, A.M.; Chiominto, A.; Di Renzi, S.; Melis, P.; Wirz, A.; Riviello, M.C.; Massari, S.; Sisto, R.; D'Ovidio, M.; Paba, E. How working tasks influence biocontamination in an animal facility. Appl. Sci. 2019, 9, 2216. [CrossRef]

(C) 2020 by the author. Licensee MDPI, Basel, Switzerland. This article is an open access article distributed under the terms and conditions of the Creative Commons Attribution (CC BY) license (http://creativecommons.org/licenses/by/4.0/). 